\title{
Tomate em pó obtido pela secagem convectiva: avaliação do processo de secagem e
}

\section{do produto final}

\author{
Tomato powder obtained by convective drying: evaluation of the drying process and the final \\ product
}

Tomate en polvo obtenido por secado convectivo: evaluación del proceso de secado y del producto

\section{Resumo}

O tomate é um fruto altamente perecível devido a sua grande quantidade de água, além de muito afetado pelos problemas pós-colheita. Uma das alternativas para diminuir perdas e desperdícios é o processamento por meio de secagem, o que torna os perecíveis mais estáveis, além de poder aproveitar os produtos, a exemplo, tomates desclassificados, para o mercado in natura. Com isso objetivou-se avaliar a influência de diferentes temperaturas (combinação de $100 / 65{ }^{\circ} \mathrm{C} ; 85^{\circ} \mathrm{C}, 75^{\circ} \mathrm{C} ; 65^{\circ} \mathrm{C}$ ) e tipos de corte $(4$ e 8 fatias) sobre a cinética de secagem e sobre a qualidade do pó de tomate. $\mathrm{O}$ processo de secagem foi avaliado em relação a taxa de secagem e perda de massa no tempo, quantificando-se ao final o rendimento. A qualidade do pó obtido foi avaliada por meio da granulometria, cor, teor de sólidos solúveis totais ( ${ }^{\circ} \mathrm{Brix}$ ), $\mathrm{pH}$ e solubilidade. A secagem do tomate na temperatura de $100 / 65^{\circ} \mathrm{C}$ fatiado em 8 partes ocorreu em menor tempo. O rendimento do pó de tomate ficou em média 5,82\%. O pó obtido do tomate cortado em 8 fatias apresentou granulometria mais fina, independente da temperatura de secagem. A temperatura de secagem à $65^{\circ} \mathrm{C}$ resultou em pó com menor escurecimento na cor. Por outro lado, o pó de tomate secado a $75^{\circ} \mathrm{C}$ apresentou a maior quantidade de ${ }^{\circ}$ Brix, e aqueles obtidos nas temperaturas 100/65 e $65{ }^{\circ} \mathrm{C}$, cortados em 4 fatias, apresentaram o maoir $\mathrm{pH}$. Em todos os tratamentos realizados obteve-se alta solubilidade, superior a $99 \%$.

Palavras-chave: Cinética de secagem; Geometria de corte; Temperatura.

\begin{abstract}
Tomato is a highly perishable fruit due to its large amount of water, in addition to being very affected by post-harvest problems. One of the alternatives to reduce losses and waste is processing through drying, which makes perishables more stable, in addition to being able to use products, such as substandard tomatoes, for the fresh market. The objective was to evaluate the influence of different temperatures (combination of $100 / 65{ }^{\circ} \mathrm{C} ; 85^{\circ} \mathrm{C}, 75^{\circ} \mathrm{C} ; 65^{\circ} \mathrm{C}$ ) and types of cut ( 4 and 8 slices) on the drying kinetics and on the quality of tomato powder. The drying process was evaluated in relation to the rate of drying and loss of mass over time, and the yield was finally quantified. The quality of the powder obtained was evaluated by means of particle size, color, total soluble solids content $\left({ }^{\circ} \mathrm{Brix}\right), \mathrm{pH}$ and solubility. Tomato drying at a temperature of $100 / 65{ }^{\circ} \mathrm{C}$, sliced into 8 parts, took place in less time. The yield of tomato powder was on average $5.82 \%$. The powder obtained from tomato cut into 8 slices had a finer granulometry, regardless of the drying temperature. The drying temperature at $65{ }^{\circ} \mathrm{C}$ resulted in powder with less darkening in color. On the other hand, tomato powder dried at $75^{\circ} \mathrm{C}$ had the highest amount of ${ }^{\circ} \mathrm{Brix}$, and those obtained at temperatures $100 / 65$ and $65{ }^{\circ} \mathrm{C}$, cut into 4 slices, had the higher $\mathrm{pH}$. In all treatments performed, high solubility was obtained, above $99 \%$.
\end{abstract}

Keywords: Drying kinetics; Cutting geometry; Temperature. 


\begin{abstract}
Resumen
El tomate es una fruta muy perecedera por su gran cantidad de agua, además de estar muy afectado por problemas poscosecha. Una de las alternativas para reducir pérdidas y desperdicios es el procesamiento por secado, lo que hace que los perecederos sean más estables, además de poder utilizar productos, como tomates de calidad inferior, para el mercado fresco. El objetivo fue evaluar la influencia de diferentes temperaturas (combinación de $100 / 65^{\circ} \mathrm{C} ; 85^{\circ} \mathrm{C}$, $75^{\circ} \mathrm{C} ; 65^{\circ} \mathrm{C}$ ) y tipos de corte (4 y 8 lonchas) en la cinética de secado y en la calidad de tomate en polvo. Se evaluó el proceso de secado en relación a la tasa de secado y pérdida de masa a lo largo del tiempo, y finalmente se cuantificó el rendimiento. La calidad del polvo obtenido se evaluó mediante tamaño de partícula, color, contenido de sólidos solubles totales ( ${ }^{\circ}$ Brix), $\mathrm{pH}$ y solubilidad. El secado del tomate a una temperatura de $100 / 65^{\circ} \mathrm{C}$, cortado en 8 partes, se llevó a cabo en menos tiempo. El rendimiento de tomate en polvo fue en promedio del 5,82\%. El polvo obtenido del tomate cortado en 8 rodajas presenta una granulometría más fina, independientemente de la temperatura de secado. La temperatura de secado a $65^{\circ} \mathrm{C}$ dio como resultado un polvo con un color menos oscuro. Por otro lado, el tomate en polvo secado a $75^{\circ} \mathrm{C}$ presentó la mayor cantidad de ${ }^{\circ}$ Brix, y los obtenidos a temperaturas de $100 / 65$ y $65^{\circ} \mathrm{C}$, cortados en 4 rodajas, presentaron el $\mathrm{pH}$ más alto. En todos los tratamientos realizados se obtuvo una alta solubilidad, superior al $99 \%$.
\end{abstract}

Palabras clave: Cinética de secado; Geometría de corte; Temperatura.

\title{
1. Introdução
}

O tomate (Lycopersicon esculentum Mill) ocupa lugar de destaque na mesa do consumidor, tanto do produto in natura, quanto industrializado na forma de vários subprodutos, como molho, extrato, polpa, pasta e o tomate seco, cujo mercado vem crescendo consideravelmente, o que leva à promissora perspectiva para a evolução do fruto (Sanjinez-Argandoña et al., 2011). Todavia, o tomate é um fruto altamente perecível devido a sua grande quantidade de água, gerando perdas póscolheita em torno de 25 a 50\% (Pacco, 2008). Por outro lado, o fruto possui ótima compatibilidade ao processo de desidratação, e a secagem vem sendo apontada em várias pesquisas (Leite et al., 2015; Furtado et al., 2014 e Machado et al., 2015) como uma das principais alternativas para reduzir as perdas pós-colheita, além de agregar valor ao produto (Coelho \& Pinto, 2011) e aumentar o seu período de conservação (Aderibigbe et al., 2018).

A secagem artificial ou desidratação é um processo que requer o uso de equipamentos para produção de calor, controlando a temperatura, a umidade relativa e a velocidade do ar de secagem (Cornejo et al., 2003). O objetivo básico da secagem é remover água do alimento até certo nível que minimize a atividade a patamares que garantam a segurança alimentar, impedindo o crescimento de microrganismos, reações químicas de deterioração e garantindo a estabilidade do produto por um longo período (Krokida \& Marinos-Kouris, 2003; Lenart, 1996). Contudo, o processo de secagem pode ser demorado e com elevado custo para indústria, como resultado de seu alto consumo energético. Para Foust et al. (1982), deve-se levar em conta, também, o fator econômico habitual dos custos de processamento que diz respeito às condições mais desejáveis do produto, do ponto de vista do mercado e vendas.

De acordo com Lenart (1996) o tempo e a temperatura de secagem podem interferir negativamente na qualidade nutricional e sensorial do produto. Logo, é indicado que o processo de desidratação seja feito o mais rápido possível para garantir produtos de qualidade à um custo razoável. Nesse sentido, os alimentos perecíveis a serem submetidos ao processo de secagem devem, de preferência, serem fatiados em tamanhos pequenos ou cortados em espessura fina afim de que a estrutura do produto não apresente tanta dificuldade para que o calor chegue até o centro geométrico e também para que seja mais fácil da água sair.

Assim o estudo dos parâmetros que influenciam o tempo de secagem e a qualidade final do produto, como a temperatura e o tipo de corte, são de interesse científico e industrial, ao passo que o processamento é uma alternativa viável para diminuir as perdas pós-colheita do tomate de mesa e para o aproveitamento dos frutos que não dão classificação para o mercado in natura. Objetivou-se com o presente estudo avaliar a influência da temperatura e do tipo de corte dos frutos de tomate sobre a cinética de secagem, rendimento de massa e características qualitativas do tomate em pó. 


\section{Material e Métodos}

Os frutos usados nesta pesquisa foram do grupo Salada longa vida (Lycopersicon esculentum Mill), obtidos no comércio local da cidade de Sinop, Mato Grosso. Foram selecionados frutos maduros de mesmo calibre e sem danos físicos ou infestações aparentes por microrganismos. Os frutos foram lavados com água corrente e acomodados sobre papel toalha.

Inicialmente foi determinado o teor de água dos frutos in natura, para essa avaliação foram utilizados 5 (cinco) tomates cortados em 8 (oito) partes, sendo retirado as sementes. As fatias foram colocadas em bandejas de alumínio e levadas para estufa a $105{ }^{\circ} \mathrm{C}$ com circulação forçada de ar. O processo foi monitorado pela perda de massa até obter peso constante, sendo constatada umidade média de 19 decimal b.s. O conhecimento da umidade inicial é fundamental para a realização da secagem, visto que o acompanhamento do processo é feito por perda de massa, até o valor de interesse.

Para a secagem os tomates foram fatiados longitudinalmente em 4 (quatro) e 8 (oito) partes (fatias) no sentido pedúnculo-ápice, retirando as sementes e a porção que as envolviam. As fatias foram separadas por tamanho e acomodadas em bandejas de alumínio, de modo que cobrissem o fundo do recipiente com apenas uma camada de tomate, como demonstrado na Figura 1.

Figura1. Preparo dos frutos de tomate em diferentes tamanhos das fatias para a secagem, (A) 4 partes e (B) em 8 partes.

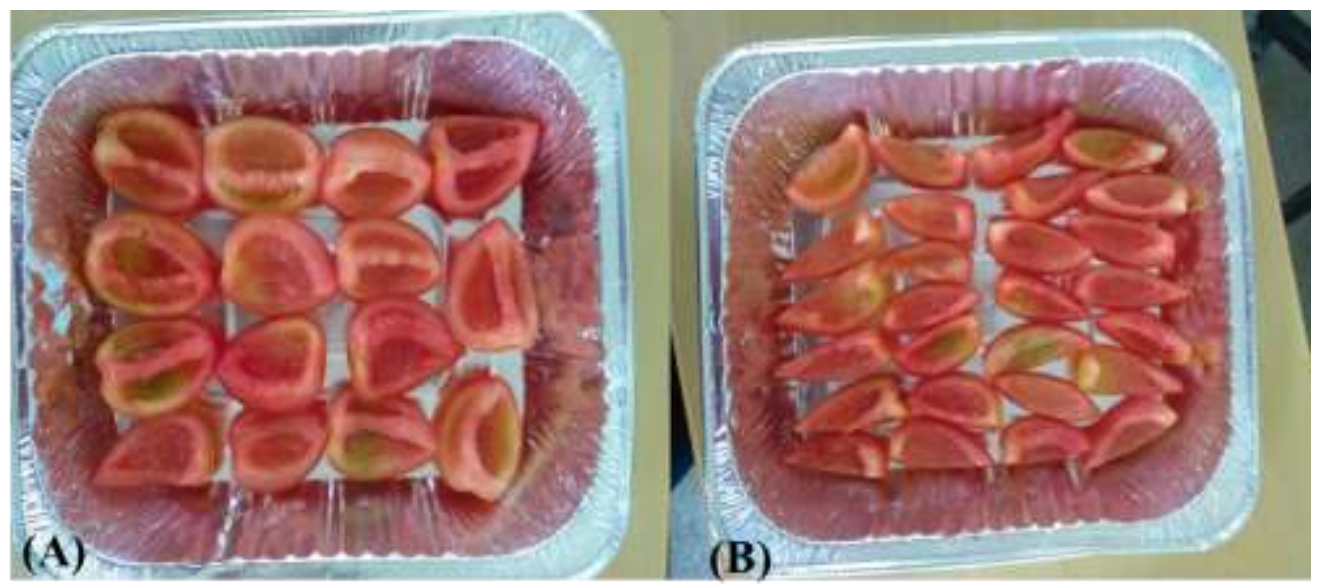

\subsection{Cinética de secagem e rendimento da massa}

Fonte: Autores.

O processo de secagem foi realizado em estufa convectiva com circulação forçada de ar na velocidade de $0,4 \mathrm{~m} \mathrm{~s}^{-1}$. As temperaturas utilizadas foram: combinação entre 100 e $65^{\circ} \mathrm{C}\left(100{ }^{\circ} \mathrm{C}\right.$ por 3 horas seguido de $\left.65^{\circ} \mathrm{C}\right) ; 85^{\circ} \mathrm{C} ; 75^{\circ} \mathrm{C} ; 65^{\circ} \mathrm{C}$. Para cada temperatura e corte foram realizadas três repetições. Antes da secagem aferiu-se o peso das bandejas e o peso total do tomate. O controle da secagem se deu por acompanhamento de perda de massa do fruto, com pesagens em intervalos de tempo pré-definidos. A secagem foi realizada até as amostras atingirem umidade próxima de 0,019 + 0,03 decimal b.s. devido a sensibilidade do fruto a perda de água. Este valor foi definido a partir de ensaios experimentais, onde objetivou-se determinar o conteúdo de água sem que houvesse comprometimento do processamento das amostras para a produção do pó.

Calculou-se a quantidade de massa de água a ser evaporada por meio da Equação 1, obtendo-se na sequência a massa final (Equação 2) correspondente a umidade desejada.

$$
\begin{gathered}
M a=M i\left[\frac{U i-U f}{100-U f}\right] \\
M f=M i-M a
\end{gathered}
$$

Equação 1

Onde: 


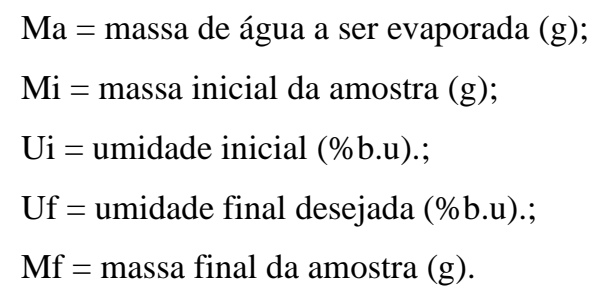

O acompanhamento da perda de massa foi realizado retirando as amostras da estufa em intervalos de tempo prédefinidos e pesando-as em balança semi-analítica $(0,01 \mathrm{~g})$. Para as temperaturas de 85,75 e $65{ }^{\circ} \mathrm{C}$, na primeira hora de secagem as amostras foram pesadas a cada 30 minutos, depois a cada 1 hora e quando próximas a atingirem a massa final eram pesadas a cada $15 \mathrm{~min}$. As amostras desidratadas na combinação $100 / 65^{\circ} \mathrm{C}$, nas primeiras 3 horas de secagem as pesagens foram realizadas cada 30 minutos, depois a cada 1 hora e quando perto do final a cada $15 \mathrm{~min}$.

Com os dados de massa e tempo foram confeccionadas as curvas da cinética de secagem e de perda de massa para obtenção do rendimento em percentual. Enquanto que o rendimento (\%) de cada amostra foi calculado a partir da massa final correlacionada com a massa inicial.

\subsection{Caracterização do pó de tomate}

Para avaliar o pó de tomate, as amostras foram trituradas durante 3 minutos em um liquidificador doméstico, e armazenadas em embalagens de polietileno até realização das análises de qualidade.

A partir do pó, foram feitas as seguintes análises: granulometria, cor, pH, teor de sólidos solúveis totais - SST ( ${ }^{\circ}$ Brix) e solubilidade.

Para a granulometria peneirou-se o pó por cerca de 30 segundos em peneira de 19 mesh, pesando a quantidade retida e a que vazou através da peneira. Por meio dessas quantidades e do peso total da amostra, foram calculadas as porcentagens retida e passante.

A cor foi avaliada de forma visual por meio de fotos, tiradas de placas de petri contendo o pó peneirado. O local das fotos foi o mesmo para todas as amostras para evitar qualquer diferença de luminosidade entre os tratamentos testados.

As determinações de $\mathrm{pH}$ e teor de sólidos solúveis totais ( ${ }^{\circ}$ Brix) foram realizadas, respectivamente, por meio de um pHmetro digital de bancada e um refratômetro manual portátil ( 0 a $32^{\circ}$ Brix). Para estas análises utilizaram-se 5 gramas de pó sendo adicionados $50 \mathrm{~mL}$ de água destilada. A homogeneização da solução foi feita com movimentos circulares até a completa dissolução do pó. Após a reidratação das amostras, aguardou-se cerca de 1 hora para as medições, em triplicata.

A solubilidade do pó foi determinada com base na metodologia proposta por Dacanal (2009), com adaptações. Adicionou-se em um béquer $200 \mathrm{ml}$ de água destilada. Com o auxílio de um agitador magnético deu-se início a agitação mantendo a altura do vórtice em $30 \mathrm{~mm}$. Após a estabilização do vórtice, com a ajuda de um funil de vidro, mantendo uma altura de $20 \mathrm{~mm}$ do vórtice, foi adicionado 2 gramas de pó de tomate. A agitação permaneceu por 1 minuto e então a solução foi imediatamente filtrada em filtro de papel previamente pesado. $\mathrm{O}$ filtro com o material retido foi levado em estufa com circulação forçada de ar a $105{ }^{\circ} \mathrm{C}$, por 24 horas. A análise foi realizada em triplicatas. Por fim, a solubilidade foi calculada por meio da Equação 3.

Onde:

$$
\mathrm{SOL}=100-\left\lfloor\frac{\mathrm{m} 2}{\mathrm{~m} 1 *(1-\mathrm{U})} \times 100\right\rfloor
$$

SOL = solubilidade $(\%) ;$
m2 = massa retida no filtro;
$\mathrm{m} 1=$ massa inicial da amostra; 
$\mathrm{U}=$ umidade inicial da amostra (decimal b.u.).

\subsection{Metodologia e análise dos dados}

A cinética de secagem e o rendimento da massa foram analisados de forma descritiva por meio de valores médios avaliados em gráficos. A granulometria e a cor do pó de tomate também foram analisadas de forma descritiva. Esses dados apresentam natureza qualitativa (Pereira et al., 2018).

Os resultados de teor de sólidos solúveis totais, $\mathrm{pH}$ e solubilidade foram avaliados pela análise de variância e comparação múltipla das médias, que foi realizada a partir do teste de Tukey a 5\% de probabilidade, utilizando o programa SISVAR (Ferreira, 2000). Esses dados possuem natureza quantitativa.

\section{Resultados e Discussão}

\subsection{Cinética de secagem e rendimento da massa}

As curvas que descrevem o comportamento da secagem do tomate em função das diferentes temperaturas e do tipo de corte estão apresentadas nas Figuras 2 e 3.

Nota-se que as curvas do tomate fatiado em 4 (Figura 2) e 8 (Figura 3) partes apresentam o período de taxa constante e decrescente de secagem como citado por Camargo (2000), o que é característico de alimentos com alto teor de água, como no caso das fatias de tomate com umidade inicial elevada, a exemplo de 19 decimal b.s. Esse mesmo efeito foi observado no estudo de Jordan et al. (2020) sobre a cinética de secagem de tomate fatiado em 4 partes e temperatura do ar de secagem de 50 e $65^{\circ} \mathrm{C}$ (secador convencional) e $45^{\circ} \mathrm{C}$ (bomba de calor).

Para o tomate fatiado em 4 partes o período constante durou até o tempo de 480 minutos nas temperaturas de 65,75 e $85^{\circ} \mathrm{C}$ e de 170 minutos na temperatura combinada de $100 / 60^{\circ} \mathrm{C}$. Para o tomate em 8 partes a taxa constante foi até o tempo de 306 minutos nas temperaturas de 65,75 e $85^{\circ} \mathrm{C}$ e de 180 minutos para $100 / 60{ }^{\circ} \mathrm{C}$. Após esses tempos, em cada temperatura e tipo de corte, inicia-se o período de taxa decrescente de secagem, durando até no final do processo. Perceba-se que o tempo de taxa de secagem constante e decrescente são influenciados pela temperatura e pelo tipo de corte. Esta influência torna-se mais significativa a medida que aumenta a diferença de temperatura de secagem entre as curvas.

As curvas das temperaturas de 75 e $85^{\circ} \mathrm{C}$ tiveram comportamento parecido no início da secagem, no entanto após 400 e 180 minutos para o tomate fatiado em 4 e 8 partes, respectivamente, esta tendência mudou e as curvas de secagem se distanciaram. Nestas condições, entende-se que o tipo de corte do tomate teve maior influência na cinética de secagem do que a temperatura. Além disso, a temperatura combinada de $100 / 60^{\circ} \mathrm{C}$ apresentou menor tempo de secagem, independente do tipo do corte, logo quanto maior a temperatura, maior será a velocidade de remoção da água do tomate.

Figura 2. Curvas de secagem, em diferentes temperaturas, para o tomate fatiado em 4 partes.

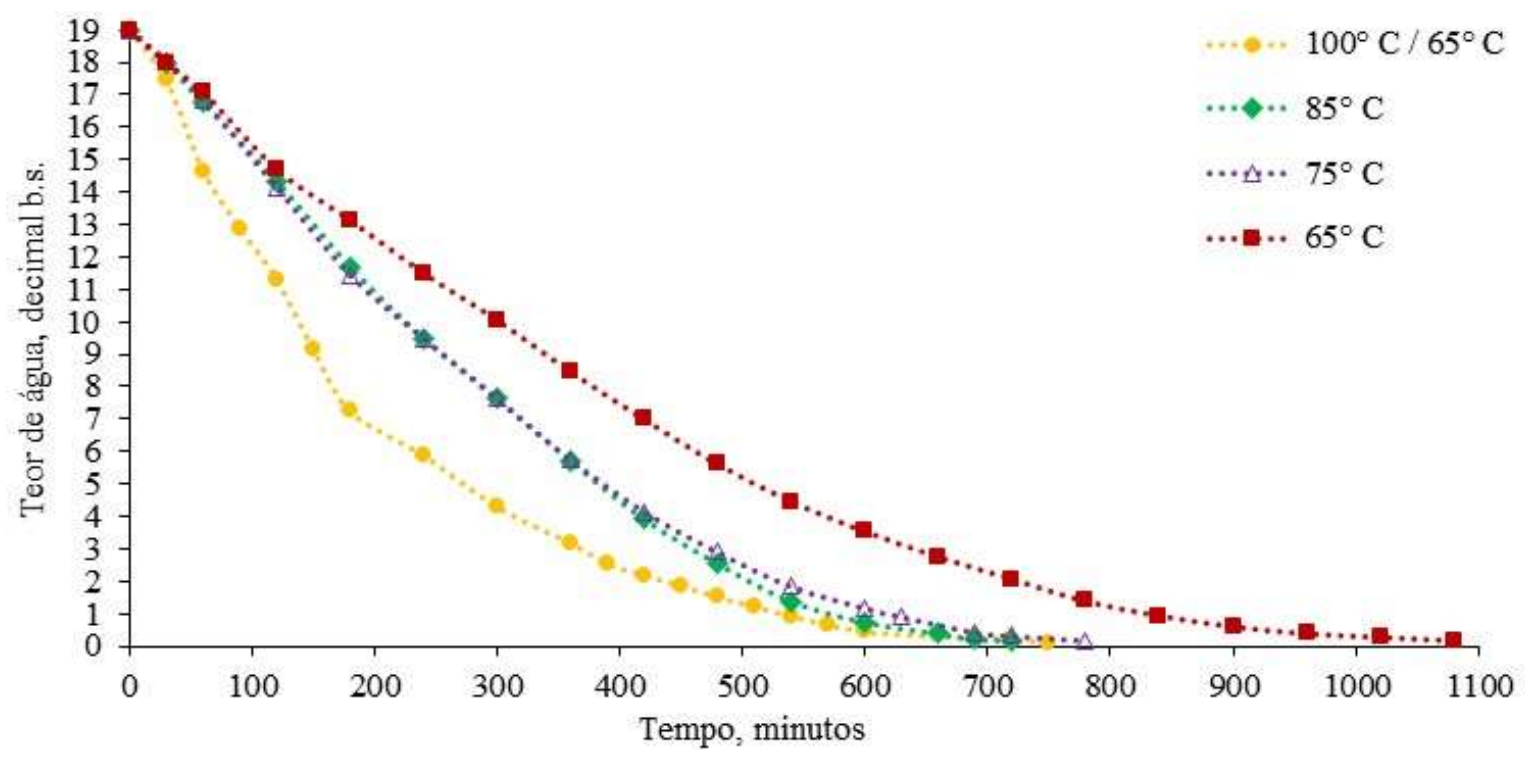


Fonte: Autores.

Figura 3. Curvas de secagem, em diferentes temperaturas, para o tomate fatiado em 8 partes.

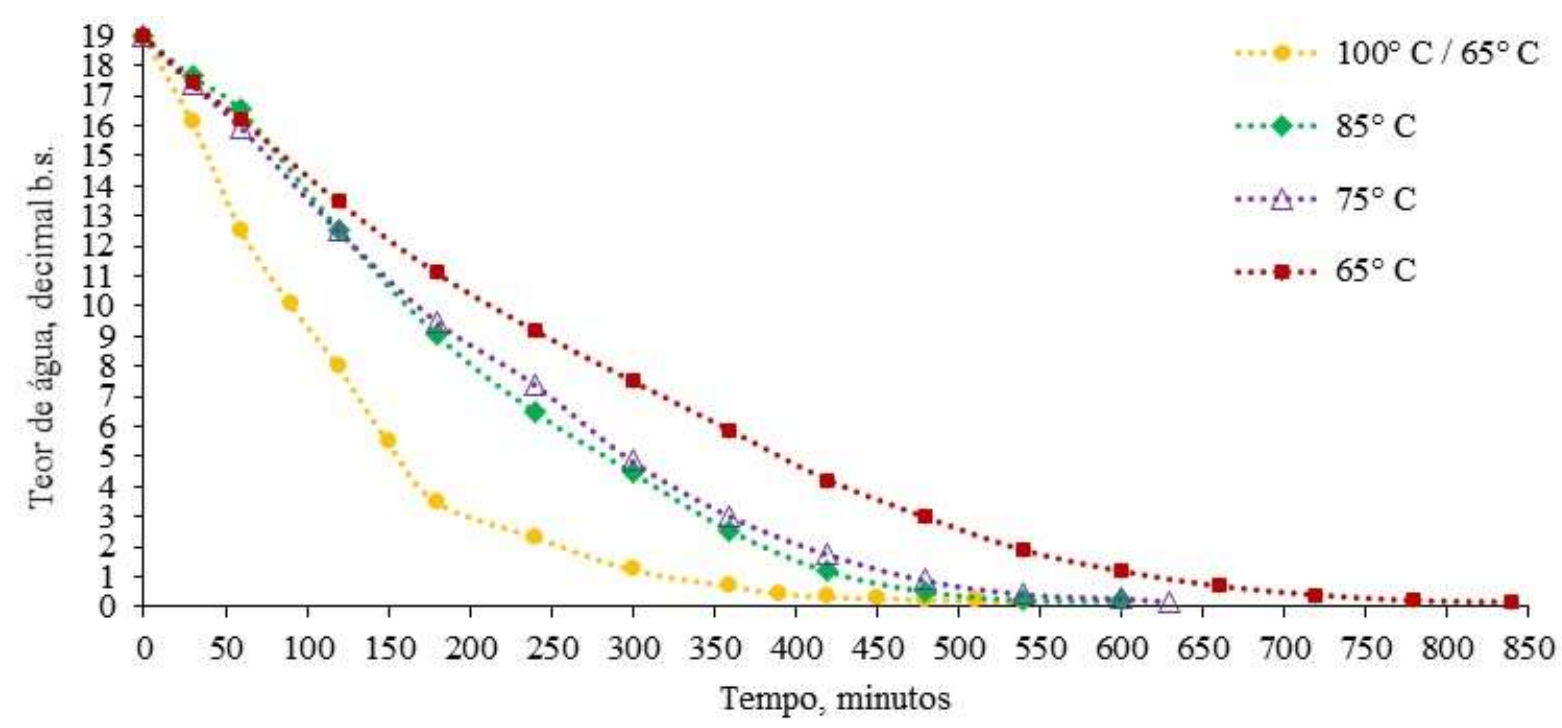

Fonte: Autores.

O tempo necessário para a secagem do tomate até na umidade final, nos dois tipos de corte e nas diferentes temperaturas, são resumidos na Tabela $1 . \mathrm{O}$ ar de secagem a $65^{\circ} \mathrm{C}$, em ambos os cortes, precisou de maior tempo para alcançar a umidade final. $\mathrm{O}$ aumento da temperatura de 65 para $75^{\circ} \mathrm{C}$ diminuiu o tempo de secagem de 5,0 e 3,7 horas para o tomate de 4 e 8 partes, respectivamente, melhorando significativamente a eficiência de secagem. No entanto, esse mesmo efeito não foi observado entre as temperaturas de 75 e $85^{\circ} \mathrm{C}$. Apesar do aumento de $10{ }^{\circ} \mathrm{C}$ no ar de secagem, a diferença no tempo entre ambas variou de 40 a 70 minutos. A maior diferença de tempo foi entre os tomates submetidos a combinação de temperaturas de $100 / 65^{\circ} \mathrm{C}$ e a de $65^{\circ} \mathrm{C}$. O fato de empregar alta temperatura no início da secagem diminuiu o tempo de secagem em torno de 6,2 e 5,3 horas para o tomate de 4 e 8 partes, respectivamente.

Verifica-se, então, que a temperatura de secagem exerce influência significativa sobre a cinética de secagem do tomate. Como observado por Sanjinez-Argandoña et al. (2011) na secagem de tomate cortado na metade e em 4 partes, a temperatura de $70{ }^{\circ} \mathrm{C}$ proporcionou o menor tempo de secagem; Corrêa Filho et al. (2015) na secagem de figo cortado longitudinalmente, a temperatura de $70{ }^{\circ} \mathrm{C}$ reduziu em $77,5 \%$ no tempo de secagem em relação a temperatura de $40{ }^{\circ} \mathrm{C}$; e D'Andrea et al. (2015) na secagem de acerola inteira, em $40{ }^{\circ} \mathrm{C}$ o tempo de secagem demorou mais de 4 dias para ser concluído, ao passo que a temperatura de $70^{\circ} \mathrm{C}$ obteve o menor tempo de secagem ( 21 horas).

A temperatura combinada de $100 / 65^{\circ} \mathrm{C}$ apresentou o menor tempo de secagem para o tomate em 8 partes, no entanto, para o tomate em 4 partes levaram o mesmo tempo que a temperatura de $85^{\circ} \mathrm{C}$. Em trabalho realizado por Raupp et al. (2007) de desidratação de tomates sob diferentes temperaturas $\left(100{ }^{\circ} \mathrm{C} ; 80{ }^{\circ} \mathrm{C}\right.$; e combinada de $100 / 80{ }^{\circ} \mathrm{C}$, sendo $100{ }^{\circ} \mathrm{C}$ por 3 horas seguido de $80^{\circ} \mathrm{C}$ ) observaram que o uso de alta temperatura no início do processo favoreceu a redução do tempo de secagem em detrimento ao teste onde foi utilizado $80^{\circ} \mathrm{C}$ do início ao fim.

Tabela 1. Tempo de secagem do tomate até a umidade final.

\begin{tabular}{ccccc}
\hline \multirow{2}{*}{ Temperatura, ${ }^{\circ} \mathrm{C}$} & \multicolumn{3}{c}{4 partes } & \multicolumn{2}{c}{8 partes } \\
\cline { 2 - 5 } & Tempo, min & Umidade, decimal b.s. & Tempo, min & Umidade, decimal b.s. \\
\hline $100 / 65$ & 750 & 0,16 & 540 & 0,19
\end{tabular}




\begin{tabular}{ccccc}
\hline & & & & \\
85 & 720 & 0,17 & 600 & 0,18 \\
75 & 780 & 0,18 & 630 & 0,19 \\
65 & 1080 & 0,18 & 840 & 0,16 \\
\hline
\end{tabular}

Fonte: Autores.

Além da importância da temperatura no processo de secagem, observou-se também que o tipo de corte possui grande influência na duração da secagem. Analisando o tipo de corte em cada nível de temperatura individualmente, tem-se que a maior diferença está entre os tomates secos a $65{ }^{\circ} \mathrm{C}$, onde o tomate fatiado em 8 partes economizou o tempo de secagem em 4 horas em relação ao tomate de 4 partes. Nota-se que nas temperaturas de $100 / 65$ e $85{ }^{\circ} \mathrm{C}$ os tomates fatiados em 4 partes apresentaram tempo semelhante, no entanto para o tomate de 8 partes houve uma diferença de 1 hora. Neste caso fica evidente que o parâmetro que teve maior influência foi o tamanho da fatia. No geral, fatias de tamanho menor diminuíram em média 3 horas o tempo de secagem para todas as temperaturas. O que está de acordo com Sanjinez-Argandoña et al. (2011) e Coelho e Pinto (2011) que também constataram menor tempo de secagem para o tomate cortado em fatias menores.

O tipo de corte possui um papel mais influente na secagem do que a temperatura, visto que os tomates fatiados em 8 partes secaram mais rapidamente que os fatiados em 4, mesmo quando a temperatura era menor. Um aumento de $10{ }^{\circ} \mathrm{C}$ na temperatura de secagem não foi o bastante para compensar a influência do aumento da área de exposta, quando comparadas as secagens a 75 e $85^{\circ} \mathrm{C}$. Resultados similares foram relatados na literatura para a secagem de espuma de patauá (Santos et al., 2019 e polpa de murta (Feitosa et al., 2017) também concluíram que os menores tamanhos secaram mais rápido, mesmo a temperaturas mais baixas.

As curvas de rendimento de massa durante secagem do tomate em função das diferentes temperaturas e do tipo de corte estão apresentadas nas Figuras 4 e 5 . Verifica-se que a redução da massa do tomate de 4 (Figura 4) e 8 (Figura 5) fatias durante a secagem foi em torno de 93,0 a $94,4 \%$, respectivamente. Vale ressaltar que a temperatura e o tipo de corte também são importantes para a taxa de perda de massa.

Observa-se que no início da secagem, mais especificamente no período de taxa constante, tem maior perda de massa devido a maior facilidade das fatias de tomate perderem água na forma de vapor para o ar de secagem, tornando-se menor a medida que o alimento entra no período de taxa de secagem decrescente. A temperatura de 100/65 ${ }^{\circ} \mathrm{C}$, após 180 minutos, diminuiu a massa do tomate fatiado em 4 e 8 partes em cerca de 59 e $78 \%$, respectivamente, enquanto que a temperatura de 65 ${ }^{\circ} \mathrm{C}$ a perda, após o mesmo tempo, foi de 29 e $39 \%$, respectivamente. Logo, o ar de secagem a $100{ }^{\circ} \mathrm{C}$ diminuiu mais da metade da massa do tomate nas primeiras 3 horas do início da secagem.

As temperaturas de 75 e $85^{\circ} \mathrm{C}$ apresentaram taxa de perda de massa equivalentes durante a secagem, independente do tipo de corte. A temperatura de $65{ }^{\circ} \mathrm{C}$ precisou de maior tempo para perder a mesma quantidade de massa que as demais temperaturas. De modo geral, para a perda de $90 \%$ de massa, o tomate em 4 fatias precisou de um pouco mais de $80 \%$ do tempo, e o cortado em 8 partes levou cerca de $10 \%$ do tempo a menos, com exceção do tomate desidratado a $75{ }^{\circ} \mathrm{C}$ que gastou, igualmente, $80 \%$ do tempo total para perder essa quantidade de massa.

Nas condições de secagem estabelecidas, o rendimento médio de massa do produto pronto ficou em torno de 5,82\%, apesar de ser um percentual baixo é importante ressaltar que a matéria prima sugerida para se obter o pó de tomate é aquela que não é viável para o mercado in natura. Ou seja, os tomates que possivelmente não seriam escolhidos pelos consumidores. Neste sentido, a desidratação além de diminuir o desperdício de alimentos, agrega valor ao produto.

Figura 4. Curvas de rendimento de massa do tomate fatiado em 4 partes secado sob diferentes temperaturas. 


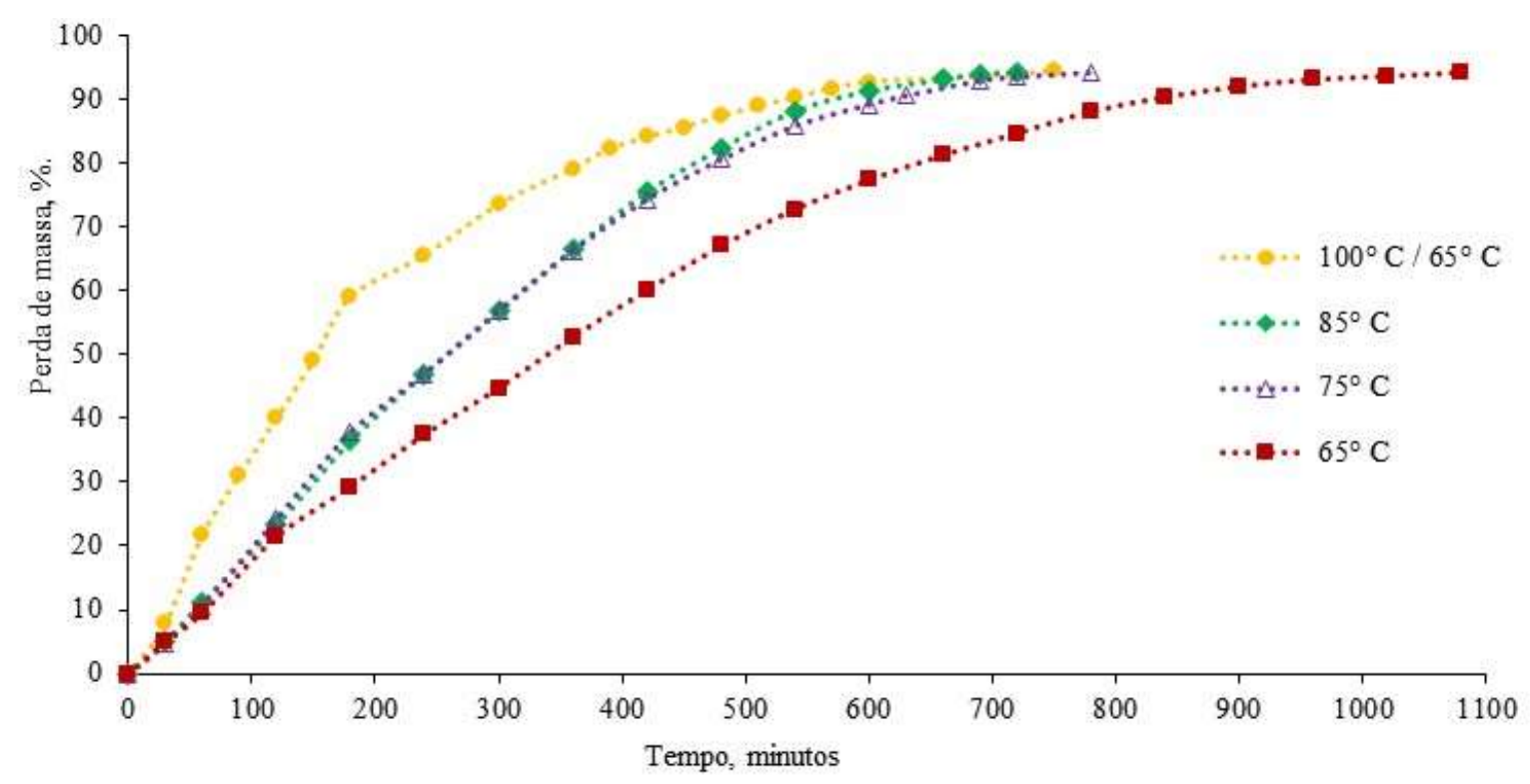

Fonte: Autores.

Figura 5. Curvas de rendimento de massa do tomate fatiado em 8 partes secado sob diferentes temperaturas.

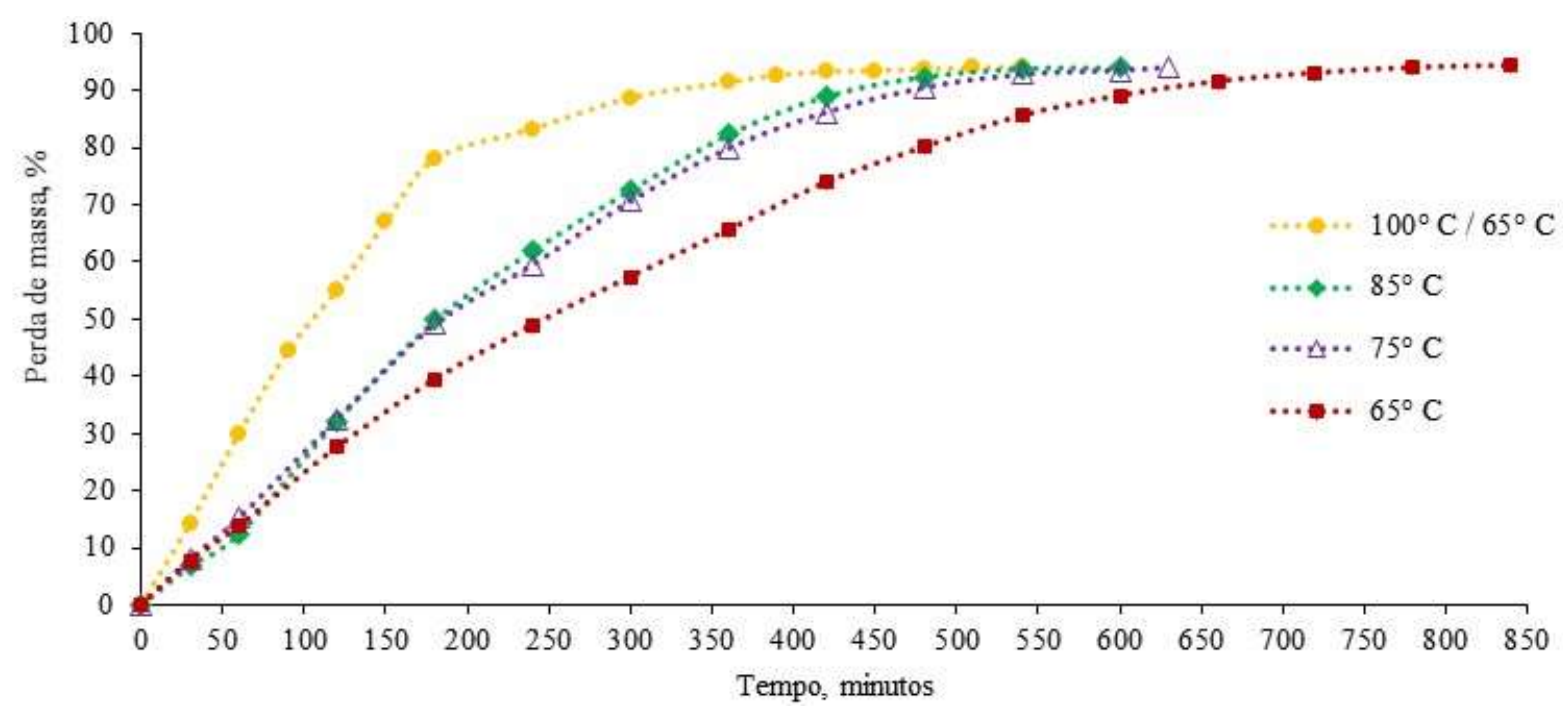

Fonte: Autores.

\subsection{Caracterização do tomate em pó}

Após a moagem do tomate seco, o pó resultante apresentou diferenças de granulometria entre as diferentes temperatura e tipo de corte. Na Tabela 2 são apresentadas a quantidade de tomate em pó que passou através da peneira (19 mesh) e o que ficou retido nela, para cada uma das temperaturas de secagem e o tipo de corte. A granulometria do pó em 4 partes obteve maior diâmetro em relação ao de 8 partes, visto que a quantidade de partículas retidas foi superior a $50 \%$, exceto quando a secagem foi realizada a $75^{\circ} \mathrm{C}$. Por outro lado, o efeito foi contrário para o pó oriundo do tomate em 8 partes, pois a quantidade que passou através da peneira foi maior que $50 \%$, com exceção da temperatura de $100 / 65^{\circ} \mathrm{C}$.

Tabela 2. Percentual de pó de tomate passante e retido na peneira.

\begin{tabular}{ccccc}
\hline \multirow{2}{*}{ Temperatura, ${ }^{\circ} \mathrm{C}$} & \multicolumn{3}{c}{4 partes } & \multicolumn{3}{c}{8 partes } \\
\cline { 2 - 6 } & Retido, $\%$ & Passante, $\%$ & Retido, $\%$ & Passante, $\%$ \\
\hline
\end{tabular}


Research, Society and Development, v. 10, n. 16, e270101623259, 2021

(CC BY 4.0) | ISSN 2525-3409 | DOI: http://dx.doi.org/10.33448/rsd-v10i16.23259

\begin{tabular}{ccccc}
\hline & & & & \\
\hline $100 / 65$ & 87,46 & 12,54 & 54,33 & 45,67 \\
85 & 54,20 & 45,80 & 32,19 & 67,81 \\
75 & 24,17 & 75,83 & 29,48 & 70,52 \\
65 & 87,06 & 12,94 & 43,10 & 56,90 \\
\hline
\end{tabular}

Fonte: Autores.

Nota-se que a granulometria do tomate em pó em 4 partes foi semelhante entre a quantidade retida e passante para as temperaturas de $100 / 65$ e $65^{\circ} \mathrm{C}$. No caso do pó retido, essas temperaturas apresentaram quantidade superior de partículas maiores, quase $90 \%$, em comparação com os demais tratamentos. O tomate desidratado na temperatura de $75{ }^{\circ} \mathrm{C}$ obteve a menor granulometria em relação as demais temperaturas, independente do tipo de corte, com valores superiores a 70\% de pó passante.

Observando os dados da Tabela 2, a umidade final das amostras desidratadas em 4 partes nas temperaturas de 100/65 e $65{ }^{\circ} \mathrm{C}$ foram as menores, e de acordo com Machado (2010) existe uma relação inversamente proporcional entre o teor de água e o diâmetro médio de partícula. Em sua pesquisa o autor verificou que o tomate em pó proveniente de fatias com menor umidade, também apresentou partículas com diâmetros maiores, corroborando com os dados no presente estudo. Ainda segundo o autor, isto é altamente desejável num processo de secagem para obtenção de um produto em pó, pois resultam em maiores rendimentos de produtos com melhores propriedades de instantaneização.

De acordo com Hogekamp e Schubert (2003) o termo "propriedades de instantaneização" é a combinação das propriedades físicas do pó associado as etapas do processo de dispersão de um pó em um líquido. De acordo com os autores um pó com boas propriedades de instantaneidade concluiu as etapas do processo de dispersão em segundos.

Na Figura 6 são apresentadas as imagens do pó de tomate obtido por meio de secagem com diferentes temperaturas e tipos de corte. É possível notar visualmente a diferença de cores entre os tratamentos e também uma perda gradual da coloração avermelhada a medida em que se aumenta a temperatura de secagem. O pó obtido a partir da secagem a $65{ }^{\circ} \mathrm{C}$ foi o que apresentou a coloração mais avermelhada, característico da fruta in natura.

O tomate em pó seco na temperatura de $75{ }^{\circ} \mathrm{C}$ apresentou uma cor tendendo para o alaranjado e com poucos pigmentos na cor vermelha, ao passo que na temperatura de $85^{\circ} \mathrm{C}$ o pó obteve uma coloração mais escura e em tons marrons, diferenciando das demais amostras. O tomate desidratado na temperatura de 100/65 ${ }^{\circ} \mathrm{C}$ atingiu coloração em tons avermelhados, sendo semelhante ao obtido na temperatura de $65^{\circ} \mathrm{C}$. Provavelmente, essa proximidade na cor aconteceu devido à redução de 5 a 6 horas no tempo de secagem na temperatura combinada $\left(100 / 65^{\circ} \mathrm{C}\right)$ e o tempo de exposição na temperatura de $65^{\circ} \mathrm{C}$, que foi superior à de $100^{\circ} \mathrm{C}$ durante o processo de secagem.

Nota-se que quando comparado o tipo de corte para uma mesma temperatura não houve diferença na tonalidade da cor, assim o tipo de corte não influenciou na coloração final do pó de tomate.

Figura 6. Caracterização da cor do pó de tomate obtido pela secagem sob diferentes temperaturas e cortes. 

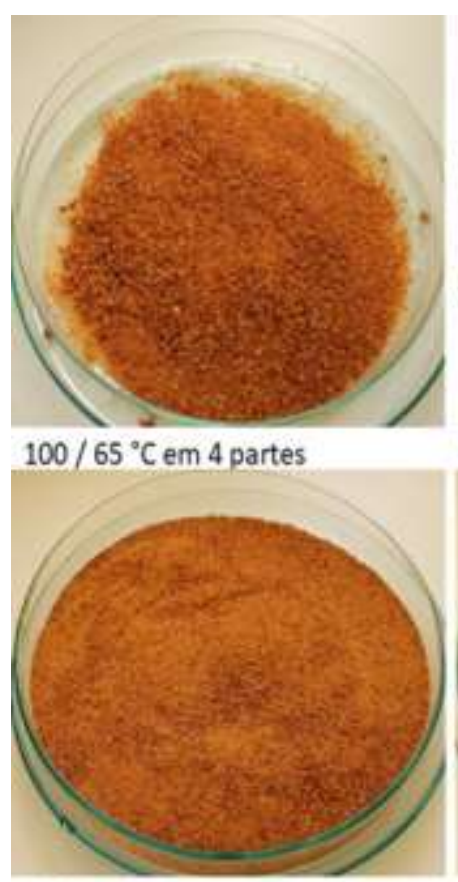

$75^{\circ} \mathrm{C}$ em 4 partes

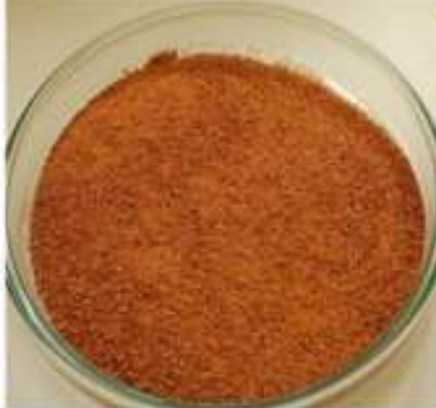

$100 / 65^{\circ} \mathrm{C}$ em 8 partes

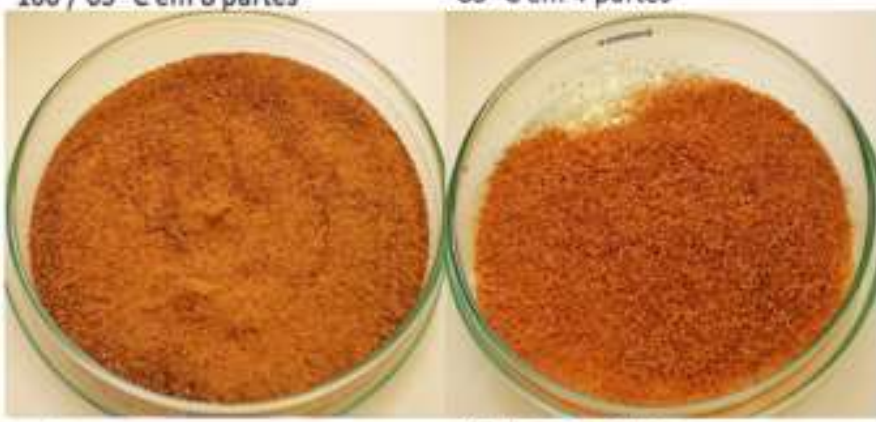

$75^{\circ} \mathrm{C}$ em 8 partes

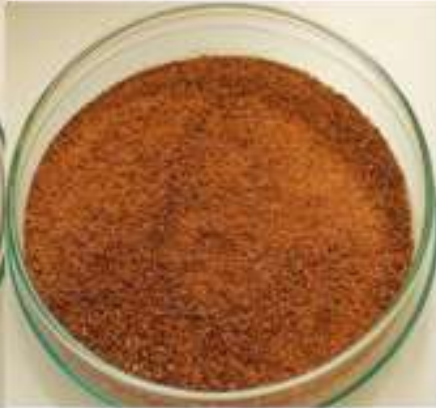

$85^{\circ} \mathrm{C}$ em 4 partes

$65^{\circ} \mathrm{C}$ em 4 partes

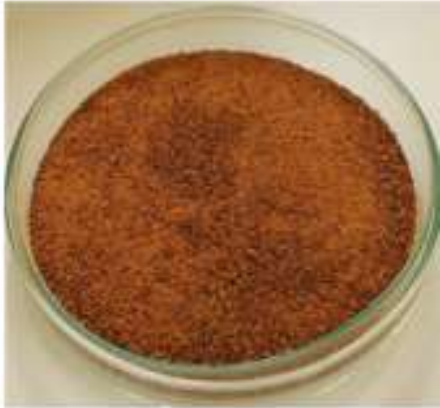

$85^{\circ} \mathrm{C}$ em 8 partes

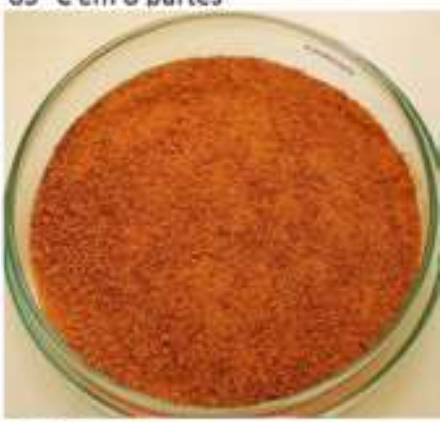

$65^{\circ} \mathrm{C}$ em 8 partes

Fonte: Autores.

Os valores médios de SST e pH para o tomate in natura foram de $3,91^{\circ}$ Brix e 4,47, respectivamente, estando próximo ao encontrado por Schwarz et al. (2013), com médias de SST de 4,84 ${ }^{\circ}$ Brix no primeiro ano de cultivo e de 4,32 no segundo ano de cultivo; para o pH os autores observaram valores médios de 4,51 e de 4,24, respectivamente, para o primeiro e segundo ano de cultivo. Verifica-se que após a desidratação do tomate, demonstrou um aumento no teor de SST, isto se deve justamente pela perda de água na secagem, tendo como principal consequência a concentração de seus nutrientes (Machado et al., 2015).

A Tabela 3 mostra o resultado obtido do teor de sólidos solúveis totais (SST) e do pH do tomate em pó. Observa-se que houve diferença significativa entre as médias de SST para o tomate em pó oriundo do corte em 4 partes entre as temperaturas de $75^{\circ} \mathrm{C}$, e $100 / 65$ e $65^{\circ} \mathrm{C}$. Para o tomate em pó em 8 fatias a diferença foi significativa apenas entre as temperaturas de $100 / 65$ e $75^{\circ} \mathrm{C}$. Não houve diferença significativa para o SST quando analisado o tipo de corte para uma mesma temperatura.

A partir do exposto pode-se dizer que para uma mesma quantidade de pó reidratado, que a temperatura de $85{ }^{\circ} \mathrm{C}$ possui valor de sólidos solúveis totais semelhantes as demais temperaturas. Além disto é importante destacar o fato do processo com combinação de temperaturas à $100 / 65^{\circ} \mathrm{C}$ não ter diferença ao processo constante à $65^{\circ} \mathrm{C}$.

Nota-se que o tomate desidratado a temperatura de $75^{\circ} \mathrm{C}$ apresentou a maior média no valor de ${ }^{\circ}$ Brix, além de diferir significativamente dos demais tratamentos, para ambos os cortes, ou seja, entre as temperaturas testadas a de $75^{\circ} \mathrm{C}$ conservou a maior quantidade de açúcar (glicose e frutose) presente no tomate in natura no decorrer da secagem. 
Tabela 3. Valores médios observados para sólido solúveis totais (SST), pH e solubilidade do tomate em pó obtido por meio de secagem a diferentes temperaturas e tipo de corte.

\begin{tabular}{|c|c|c|c|c|c|c|}
\hline \multirow{2}{*}{ Temperatura, ${ }^{\circ} \mathrm{C}$} & \multicolumn{2}{|c|}{ SST, ${ }^{\circ}$ Brix } & \multicolumn{2}{|c|}{$\mathrm{pH}$} & \multicolumn{2}{|c|}{ Solubilidade, $\%$} \\
\hline & 4 partes & 8 partes & 4 partes & 8 partes & 4 partes & 8 partes \\
\hline $100 / 65$ & $5,87 \mathrm{aA}$ & $6,00 \mathrm{aA}$ & $4,37 \mathrm{aA}$ & $4,34 \mathrm{aB}$ & $99,56 \mathrm{aA}$ & $99,55 \mathrm{aA}$ \\
\hline 85 & $6,80 \mathrm{abA}$ & $6,80 \mathrm{abA}$ & $4,13 \mathrm{cA}$ & $4,14 \mathrm{bA}$ & $99,59 \mathrm{abA}$ & $99,61 \mathrm{aA}$ \\
\hline 75 & $7,60 \mathrm{bA}$ & $7,40 \mathrm{bA}$ & $4,19 \mathrm{bA}$ & $4,17 \mathrm{bB}$ & 99,63 bA & $99,62 \mathrm{aA}$ \\
\hline 65 & $6,33 \mathrm{aA}$ & $6,87 \mathrm{abA}$ & $4,35 \mathrm{aA}$ & $4,31 \mathrm{aB}$ & $99,61 \mathrm{abA}$ & $99,62 \mathrm{aA}$ \\
\hline $\mathrm{CV}, \%$ & \multicolumn{2}{|c|}{6,75} & \multicolumn{2}{|c|}{0,30} & \multicolumn{2}{|c|}{0,03} \\
\hline
\end{tabular}

Médias seguidas pela mesma letra minúscula na coluna e maiúscula na linha, para cada propriedade, não diferem entre si pelo teste de Tukey a 5\%. Fonte: Autores.

Observa-se que a média do $\mathrm{pH}$ do tomate desidratado foi inferior ao tomate in natura. Além disso, tanto a temperatura quanto o tipo de corte influenciaram no valor do pH do tomate em pó. Os valores do pH do tomate em 4 e 8 partes diminuíram com o aumento da temperatura, exceto para a temperatura de $100 / 65^{\circ} \mathrm{C}$. Nota-se que houve diferença significativa entre o tipo de corte do tomate, com exceção para a temperatura de $85^{\circ} \mathrm{C}$, fora isso o tomate fatiado em 8 partes apresentou as menores médias do pH quando comparado com o de 4 partes. Não houve diferença estatística entre o ar de secagem de $100 / 65$ e $65^{\circ} \mathrm{C}$, ou seja, o uso de alta temperatura no início da secagem não interferiu no pH, independente do corte utilizado. Também não houve diferença entre as temperaturas de 75 e $85^{\circ} \mathrm{C}$ no tomate fatiado em 8 partes, ao contrário do tomate cortado em 4 partes.

A solubilidade do tomate em pó obtido por meio de secagem com diferentes temperaturas e tipos de corte está apresentando na Tabela 3. Verifica-se que em todos os tratamentos o tomate em pó obteve alta solubilidade, com valores superiores a 99\%. Houve diferença significativa na temperatura apenas para o tomate fatiado em 4 partes, onde a única diferença nas médias foi entre as temperaturas de $100 / 65$ e $75^{\circ} \mathrm{C}$. Cujo processo de secagem à $75^{\circ} \mathrm{C}$ resultou em um pó mais solúvel. O tipo de corte também não apresentou diferença estatística entre as médias testadas, ou seja, o tipo de corte não influência na solubilidade do tomate em pó.

Estes valores estão superiores a outros trabalhos que usaram processos de secagem diferentes para a produção do tomate em pó, como Castoldi et al. (2015) e Abul-Fadl e Ganem (2011) por refractance window, e Machado (2010) por atomização. O conhecimento da solubilidade dos alimentos em pó na água é importante, pois a sua dissolução (etapa do processo de reidratação) no meio líquido depende do quão solúvel é a partícula (Forny et al., 2011). Além disso, Abul-Fadl e Ganem (2011) afirmam que a exposição do produto a temperaturas elevadas por maiores tempos durante o processo de secagem pode reduzir a solubilidade dos pós. Esse fato não foi observado neste estudo, uma vez que todas as médias de solubilidade apresentaram valores próximos. Isso significa que as temperaturas testadas não provocaram danos expressivos na estrutura do tomate, favorecendo a reidratação do pó de tomate.

\section{Considerações Finais}

A temperatura e o tipo de corte influenciam na cinética de secagem do tomate, ou seja, o aumento da temperatura e a redução do tamanho da fatia do tomate resultam na secagem em menor tempo. Assim, o tomate fatiado em 8 partes desidratado na temperatura combinada de $100 / 65^{\circ} \mathrm{C}$ (secados a $100{ }^{\circ} \mathrm{C}$ por 3 horas seguido de $65^{\circ} \mathrm{C}$ ) leva menos tempo para alcançar a umidade final $(0,019+0,03$ decimal b.s. $)$.

O rendimento médio de massa do tomate em pó é em torno de 5,82\%, independente da temperatura avaliada e o tipo de corte do fruto. A desidratação do tomate in natura para obtenção de pó é mais rápida quanto maior for a temperatura do ar de secagem e em fatias menores.

Em relação as características qualitativas do tomate em pó, nota-se que a temperatura de $75^{\circ} \mathrm{C}$ e o tomate cortado em 
fatias menores resultam em pó com partículas mais finas. A secagem causa escurecimento na tonalidade da cor do tomate em pó, sendo proporcional ao aumento da temperatura, porém o tipo de corte não altera a cor do pó. A temperatura de $75{ }^{\circ} \mathrm{C}$ mantém a maior quantidade de teor de sólidos solúveis totais, independente do tipo de corte. O incremento da temperatura associado com o tomate fatiado em 4 partes resultam no aumento do pH. O pó de tomate possui solubilidade superior a $99 \%$, independente da temperatura de secagem e o tipo de corte.

Por fim, os pós oriundos da secagem a 100/65 e $65{ }^{\circ} \mathrm{C}$ apresentam características qualitativas semelhantes para a granulometria, cor, sólidos solúveis totais, $\mathrm{pH}$ e solubilidade. Logo, a combinação de temperatura de $100 / 65^{\circ} \mathrm{C}$ pode ser uma escolha viável para aumentar a eficiência de secagem num espaço de tempo menor, mas sem causar danos qualitativos ao produto seco.

Os resultados encontrados neste estudo auxiliaram no entendimento de vários aspectos importantes sobre a cinética secagem e qualidade do pó obtido do tomate desidratado, entretanto, questões relativas a composição nutricional não foram levantadas. Estudos futuros deverão inferir a manutenção das propriedades químicas do tomate, após passar por processos de secagem a altas temperaturas.

\section{Referências}

Abul-Fadl, M. M., \& Ghanem, T. H. (2011). Effect of Refractance Window (RW) drying method on quality criteria of produced tomato powder as compared to the convection drying method. World Applied Science Journal, 15(7): 93-96. https://www.idosi.org/wasj/wasj15(7)11/7.pdf

Aderibigbe, O. R., Owolade, O. S., Egbekunle, K.O., Popoola, F. O., \& Jiboku, O. O. (2018). Quality attributes of tomato powder as affected by different predrying treatments. International Food Research Journal, 25(3):1126-1132. https://eurekamag.com/research/070/868/070868687.php

Camargo, G. A. (2000). Secagem de tomate (lycopersicon esculentum mill) para conserva: estudo de parâmetros com base na qualidade final. Dissertação (Mestrado em Engenharia Agrícola) - Faculdade de Engenharia de Alimentos, Universidade Estadual de Campinas, Campinas, 87p.

Castoldi, M., Zotarelli, M. F., Durigon, A., Carciofi, B. A. M., \& Laurindo, J. B. (2015). Production of tomato powder by refractance window drying. Drying Technology, 33(12): 1463-1473. https://doi.org/10.1080/07373937.2014.989327

Coelho, K. D., \& Pinto, L. A. A. (2011). Caracterização da secagem convectiva de tomate (lycopersicon esculentum mill) em camada delgada. Vetor, 21(2): 521. Retrieved from https://periodicos.furg.br/vetor/article/view/2765

Cornejo, F. E. P., Nogueira, R. I., \& Wilberg, V. C. (2003). Secagem como Método de Conservação de Frutas. Embrapa Agroindústria de Alimentos, p.22 (Documentos 54).

Corrêa-Filho, L. C., Andrade, E. T., Martinazzo, A. P., D’Andrea, E. M., Sousa, F. A., \& Figueira, V. G. (2015). Cinética de secagem, contração volumétrica e análise da difusão líquida do figo (Ficus carica L.). Revista Brasileira de Engenharia Agrícola e Ambiental, 19(8), 797-802. http://dx.doi.org/10.1590/18071929/agriambi.v19n8p797-802

Dacanal, G. C. (2009). Aglomeração de polpa de acerola e proteína isolada de soja em pó em leito fluidizado cônico e pulsado. Tese (Doutorado em Engenharia de Alimentos) - Faculdade de Engenharia de Alimentos, Universidade Estadual de Campinas, Campinas, 202p.

D’Andrea, E. M., Andrade, E. T., Corrêa-Filho, L. C, Sousa, F. A., \& Figueira, V. G. (2015). Análise da cinética de secagem, contração volumétrica e difusão líquida da acerola "in natura". Revista Brasileira de Produtos Agroindustriais, 17(4): 399-408. http://www.deag.ufcg.edu.br/rbpa/rev174/Art1747.pdf

Feitosa, R. M., Figueirêdo, R. M. F., Queiroz, A. J. M., Lima, F. C. S., \& Oliveira, E. N. A. (2017). Drying and characterization of myrtle pulp. Revista Brasileira de Engenharia Agrícola e Ambiental, 21(12), 858-864. http://dx.doi.org/10.1590/1807-1929/agriambi.v21n12p858-864

Ferreira, D. F. (2000). Análises estatísticas por meio do Sisvar para Win dows versão 4.0. In: Reunião anual da região brasileira da sociedade internacional de biometria, 45., 2000. Anais. SIB: 255-258.

Forny, L., Marabi, A., \& Palzer, S. (2011). Wetting, disintegration and dissolution of agglomerated water soluble powders. Powder Technology, 206: 72-78. doi: http://dx.doi.org/10.1016/j.powtec.2010.07.022

Foust, A. S., Wenzel, L. A., Clump, C. W., Maus, L., \& Andersen, L. B. (1982). Princípios das operações unitárias. Rio de Janeiro, Guanabara Dois, 670p.

Furtado, G. F., Silva, F. S., Porto, A. G., \& Santo, P. (2014). Secagem de abacaxi (Ananás comosus (1.) Merril), variedade pérola utilizando a técnica de camada de espuma. Revista Brasileira de Produtos Agroindustriais, 16(4): 387-394. doi: http://dx.doi.org/10.15871/1517-8595/rbpa.v16n4p387-394

Hogekamp, S., \& Schubert, H. (2003). Rehydration of food powders. Food Science and Technology International, 9(3): 223-235. https://doi.org/10.1177\%2F1082013203034938

Jordan, R. A., Quequeto, W. D., Martins, E. A. S., Siqueira, V. C., Hoscher, R. H., Silva, R. V., Melo, C. D. O. M., Freitas, R. L., Battilani, M., \& Oliveira, F. C. (2020). Cinética de secagem de tomate em secador convencional e bomba de calor. Research, Society and Development, 9(9): 1-20. 10.33448/rsdv9i9.8024. 
Research, Society and Development, v. 10, n. 16, e270101623259, 2021

(CC BY 4.0) | ISSN 2525-3409 | DOI: http://dx.doi.org/10.33448/rsd-v10i16.23259

Krokida, M. K., \& Marinos-Kouris, D. (2003). Rehydration kinetics of dehydrated products. Journal of Food Engineering, 57: 1-7. http://dx.doi.org/10.1016/S0260-8774(02)00214-5

Leite, A. L. M., Silva, F. S., Porto, A. G., Piasson, d., \& Santos, P. (2015). Contração volumétrica e cinética de secagem de fatias de banana variedade Terra. Pesquisa Agropecuária Tropical, 45(2): 155-162. doi: https://doi.org/10.1590/1983-40632015v4530270

Lenart, A. (1996). Osmo-convective drying of fruits and vegetables: technology and application. Drying Technology, 14: $391-413$. https://doi.org/10.1080/07373939608917104

Machado, A. V., Souza, J. A., \& Novaes, R. S. (2015). Estudo cinético da secagem da uva Isabel para produção de uva passa. Revista Verde de agroecologia e desenvolvimento sustentável, 10(1): 47-51. https://doi.org/10.18378/rvads.v10i1.3324

Machado, V. G. (2010). Obtenção de tomate em pó por atomização: influência das variáveis de processo na qualidade do produto. Dissertação (Mestrado em Engenharia de Alimentos) - Faculdade de Engenharia de Alimentos, Universidade Estadual de Campinas, Campinas, 158p.

Pacco, H. C. (2008). Desenvolvimento de um sistema de bomba de calor água/água para resfriamento e secagem de tomates. Tese (Doutorado em Engenharia Agrícola) - Faculdade de Engenharia Agrícola, Universidade Estadual de Campinas, Campinas.

Pereira, A. S., Shitsuka, D. M., Parreira, F. J., \& Shitsuka, R. (2018). Metodologia da pesquisa científica. UFSM.

Raupp, D., Gabriel, L. S., Vezzaro, A. F., Daros, P. A., Chrestani, F., Gardingo, J. R., \& Borsato, A. V. (2007). Tomate longa vida desidratado em diferentes temperaturas de secagem. Acta Scientiarum Agronomy, 29(1): 33-39. https://doi.org/10.4025/actasciagron.v29i1.63

Sanjinez-Argandoña, E. J., Branco, I. G., Bittencourt, T. U., \& Munhoz, C. L. (2011). Influência da geometria e da temperatura na cinética de secagem de tomate (Lycopersicum esculentum). Ciência e Tecnologia de Alimentos, 31(2): 308-312. https://doi.org/10.1590/S0101-20612011000200005

Santos, D. C., Costa, T. N., Franco, F. B., Castro, R. C., Ferreira, J. P. L., Souza, M. A. S., \& Santos, J. C. P. (2019). Drying kinetics and thermodynamic properties of patawa pulp (Oenocarpus bataua Mart.). Brazilian Journal of Food Technology, 22(e2018305): 1-11. https://doi.org/10.1590/1981-6723.30518

Schwarz, K, Resende, J. T. V., Preczenhak, A. P., Paula, J. T., Faria, M.V., \& Dias, D.M. (2013). Desempenho agronômico e qualidade físico-química de híbridos de tomateiro em cultivo rasteiro. Horticultura Brasileira, 31: 410-418. https://doi.org/10.1590/S0102-05362013000300011 